\title{
Porta-enxertos para tomateiro conduzido com quatro hastes ${ }^{1}$
}

\author{
Rafaelle Fazzi Gomes ${ }^{2 *}$, Renata Castoldi ${ }^{3}$, Danilo Mesquita Melo ${ }^{4}$, Leila Trevisan Braz², \\ Durvalina Maria Mathias dos Santos ${ }^{5}$
}

$10.1590 / 0034-737 X 201764020011$

\begin{abstract}
RESUMO
Uma das formas de melhoria da qualidade e da produção do tomateiro é a adoção de técnicas adequadas de manejo da cultura, destacando-se o uso da enxertia e o método de condução das plantas. Contudo, no Brasil, há falta de informações que estimulem essas práticas. Por isso, este trabalho teve por objetivo avaliar o desempenho de portaenxertos para tomateiro, com vigoroso sistema radicular, conduzido com quatro hastes, em fibra da casca de coco, em ambiente protegido. Adotou-se o espaçamento de 2,0 m entrelinhas e 0,40 m entre plantas. Para isso, foi utilizado o delineamento em blocos casualizados, com quatro tratamentos e seis repetições, sendo, os tratamentos, dois portaenxertos ('Maxifort' e 'Multifort'), autoenxertia ('Alambra' em 'Alambra'), e o pé franco ('Alambra'). Cada parcela foi constituída de 20 plantas, sendo avaliadas as 14 plantas centrais. Não houve efeito significativo no uso dos portaenxertos sobre as características de produção e de qualidade dos frutos. Na avaliação do estado nutricional, houve diferenças para os teores de P, Mg e Ca em plantas enxertadas. Portanto, os porta-enxertos 'Maxifort' e 'Multifort', cultivados nas condições em que o experimento foi realizado, não proporcionaram aumento da produção e da qualidade dos frutos.
\end{abstract}

Palavras-chave: Solanum lycopersicum L.; enxertia; fibra da casca de coco; cultivo protegido; número de hastes.

\section{ABSTRACT}

\section{Rootstocks for tomato conducted with four stems}

One way of improving the quality and production of tomato is the adoption of appropriate techniques for crop management, especially the use of grafting and conduction method of the plants. However, in Brazil, there is a lack of information to encourage such practices. Therefore, this study aimed to evaluate the performance of rootstocks for tomato plants, with vigorous root system, conducted with four stems, in coconut fiber, under protected cultivation. The adopted spacing was $2.0 \mathrm{~m}$ between rows and $0.40 \mathrm{~m}$ between plants. For this, we used a randomized block design with four treatments and six replications. The treatments consisted of two rootstocks ("Maxifort" and "Multifort"), self-grafted ("Alambra" in "Alambra"), and ungrafted ("Alambra"). Each plot consisted of 20 plants, out of which the 14 central plants were evaluated. There was no significant effect on yield and fruit quality. In the assessment of nutritional status, there were no differences in the levels of $\mathrm{P}, \mathrm{Mg}$, and $\mathrm{Ca}$ in grafted plants. Therefore, the rootstocks Maxifort and Multifort, grown under conditions in which the experiment was conducted, did not increase the production and quality of fruits.

Key words: Solanum lycopersicum L.; grafting; coconut fiber; protected cultivation; stem number.

\footnotetext{
Submetido em 31/07/2014 e aprovado em 14/02/2017.

${ }^{1}$ Este trabalho é parte da dissertação de mestrado da primeira autora.

${ }^{2}$ Universidade Estadual Paulista, Departamento de Produção Vegetal, Jaboticabal, São Paulo, Brasil. rafaelle.fazzi@yahoo.com.br; leilatb@fcav.unesp.br

${ }_{3}^{3}$ Universidade Estadual de Minas Gerais, Passos, Minas Gerais, Brasil. rcastoldi@gmail.com.

${ }^{4}$ Universidade Federal Rural da Amazônia, Parauapebas, Pará, Brasil. danilo.melo@ufra.edu.br.

${ }^{5}$ Universidade Estadual Paulista, Departamento de Biologia aplicada a Agropecuária, Jaboticabal, São Paulo, Brasil. dumaria@ fcav.unesp.br

*Autora para correspondência: rafaelle.fazzi@yahoo.com.br
} 


\section{INTRODUÇÃO}

O tomateiro (Solanum lycopersicum L.) é uma das olerícolas mais importantes do mundo (Gruda, 2009). Sua produção mundial aumentou cerca de $40 \%$ durante os últimos dez anos e o cultivo em casa de vegetação tornouse economicamente importante (He et al., 2009). Para o Brasil, dados da Food and Agriculture Organization mostraram que a produção no ano de 2011 foi de cerca de 4,4 milhões de toneladas, fazendo do país o oitavo maior produtor mundial (FAO, 2013).

Diversos países, como a Espanha, já relatam trabalhos a respeito do uso da enxertia como forma de aumentar a qualidade e a produção dos frutos, a partir do uso de porta-enxertos com vigoroso sistema radicular, permitindo otimização da absorção de nutrientes (Flores et al., 2010; Schwarz et al., 2012). Esses porta-enxertos podem promover melhor crescimento das plantas, aumentos do rendimento e da tolerância a baixas temperaturas, além de reduzir os danos causados por patógenos (Louws et al., 2010). Segundo Martínez-Ballesta et al. (2010), plantas de tomateiro enxertadas mostraram maior absorção de água e minerais, em comparação com as plantas não enxertadas (pés francos), como consequência do sistema radicular vigoroso usado como porta-enxerto, conferindo, com isso, aumento da produção. Outra forma de melhoria da qualidade e da produção de tomateiros é por adoção de técnicas adequadas de manejo da cultura, destacando-se o tutoramento, a forma de condução e o espaçamento (Marim et al., 2005).

Em casa de vegetação, o tomateiro deve ser tutorado e a condução da planta com uma haste é o método mais utilizado no Brasil (Silva et al., 1997). No entanto, Filgueira (1982) já relatava que plantas de tomateiro poderiam ser conduzidas com número de hastes variando de uma a quatro. Charlo et al. (2009), estudando o efeito de diferentes sistemas de orientação em tomateiro, verificaram que a maior produção foi observada em plantas conduzidas com duas hastes, graças ao maior número de flores e à maior área foliar fotossintetizante. Assim, acredita-se que maiores números de hastes por planta de tomateiro proporcionem maior número de rácemos e de inflorescências e, consequentemente, maior produção de frutos.

Trabalhos de pesquisas, no Brasil, envolvendo a condução de tomateiro com quatro hastes, são difíceis de serem encontrados na literatura. Sabe-se que esse tipo de condução está sendo muito utilizado na Europa, por produtores de hortaliças, juntamente com mudas enxertadas, conseguindo-se com isso altas produtividades.

Diante disso, este trabalho teve por objetivo avaliar o desempenho de porta-enxertos para tomateiro conduzido com quatro hastes, em fibra da casca de coco, em ambiente protegido.

\section{MATERIAL E MÉTODOS}

O experimento foi conduzido em casa de vegetação, no Setor de Olericultura e Plantas Aromático-Medicinais, da Faculdade de Ciências Agrárias e Veterinárias (UNESPFCAV), Câmpus de Jaboticabal, SP. A altitude local é de $614 \mathrm{~m}$ e, as coordenadas, $21^{\circ} 14^{\prime} 05^{\prime \prime} \mathrm{S}$ e 48 $17^{\circ}$ '09" O. O clima, segundo a classificação de Köppen, é do tipo Aw com transição para Cwa.

As médias de temperatura e de umidade relativa do ar (UR) durante os meses de condução do experimento foram: junho $\left(25,23^{\circ} \mathrm{C}\right.$ e UR $\left.65,75 \%\right)$; julho $\left(18,32^{\circ} \mathrm{C}\right.$ e UR $56,17 \%)$; agosto $\left(19,62^{\circ} \mathrm{C}\right.$ e UR $\left.56,70 \%\right)$; setembro (20,87 ${ }^{\circ} \mathrm{C}$ e UR 59,74\%); outubro $\left(29,47^{\circ} \mathrm{C}\right.$ e UR 56,87) e novembro $\left(25,70^{\circ} \mathrm{Ce}\right.$ UR $\left.59,88 \%\right)$.

O delineamento experimental adotado foi em blocos ao acaso, com quatro tratamentos e seis repetições. Os tratamentos foram: dois porta-enxertos ('Maxifort' e 'Multifort'), autoenxertia ('Alambra' em 'Alambra'), e pé franco ('Alambra'). A parcela experimental foi constituída de 20 plantas, sendo consideradas 14 plantas como área útil.

Como porta-enxertos, utilizaram-se: Maxifort ${ }^{\circledR}$ (portaenxerto para cultivo de tomateiro e berinjeleira) e Multifort ${ }^{\circledR}$ (porta-enxerto adequado para tomateiro e berinjeleira, com resistência à raça 3 de Fusarium f.sp. oxysporum lycopersici) (Ruiter Seeds, 2013).

Já para enxerto foi utilizado o híbrido Alambra ${ }^{\circledR}$, cultivar do grupo saladinha, com característica "longa vida", precoce e de crescimento indeterminado, resistência à murcha de Verticillium, murcha de Fusarium, nematoide e Cladosporium (Clause Vegetable Seeds, 2013).

As semeaduras dos porta-enxertos e enxertos foram realizadas em bandejas de poliestireno expandido, com 128 células, preenchidas com substrato comercial Bioplant ${ }^{\circledR}$. A semeadura dos enxertos foi realizada dez dias após a semeadura dos porta-enxertos, para que houvesse semelhanças nos diâmetros no momento da enxertia. Após a semeadura, as bandejas foram acondicionadas em casa de vegetação, recebendo irrigação de duas a três vezes ao dia.

Para a enxertia, foi utilizado o método da garfagem de fenda simples, sendo realizadas 70 enxertias para cada tratamento.

Após as enxertias, as mudas foram mantidas por 11 dias em câmara úmida, com solução nutritiva, até o pegamento e a cicatrização da região enxertada. A taxa de pegamento foi determinada por meio da quantidade de enxertias que sobreviveram aos 11 dias após sua realização.

As mudas foram transplantadas para vasos plásticos com capacidade total de $13 \mathrm{dm}^{3}$, com substrato composto por fibra da casca de coco Golden Mix (misto), que apresenta as seguintes características físicas: porosidade total de $94 \%$; capacidade de aeração de $35 \%$ e capacidade de retenção de água de 40\% (Amafibra, 2014). 
As plantas foram cultivadas em casa de vegetação do tipo arco, com $51 \mathrm{~m}$ de comprimento e $14 \mathrm{~m}$ de largura, pé direito de 3,5 m, coberta com polietileno de baixa densidade (PEBD) e proteção lateral com tela preta de sombreamento de $50 \%$. O espaçamento adotado foi de 2,0 m entrelinhas e 0,40 m entre plantas.

Para determinação das quatro hastes, as plantas foram podadas a partir da quarta folha totalmente expandida, sendo mantidas as brotações que surgiram na base dos pecíolos, as quais foram conduzidas em "V", com fitilhos. Foram conduzidas duas hastes para cada lado da linha de plantio, com inclinação de $45^{\circ}$, até atingirem a altura de 2,0 $\mathrm{m}$ do solo, quando foi realizada a poda apical. A desbrota e o amarrio das hastes foram realizados semanalmente.

O método de fertirrigação utilizado foi por gotejamento, sendo fixados dois gotejadores por vaso. A solução nutritiva fornecida seguiu as recomendações propostas por Castellane \& Araújo (1994), para cada fase de desenvolvimento do tomateiro, constando da seguinte formulação por 1.500 L de água: a) para a fase vegetativa (300 g nitrato de potássio; $750 \mathrm{~g}$ de sulfato de magnésio; $405 \mathrm{~g}$ de fosfato de potássio; $150 \mathrm{~g}$ de sulfato de potássio; $750 \mathrm{~g}$ de nitrato de cálcio). b) para as de floração e frutificação (300 g nitrato de potássio; 750 g de sulfato de magnésio; $405 \mathrm{~g}$ de fosfato de potássio; $150 \mathrm{~g}$ de sulfato de potássio; $1020 \mathrm{~g}$ de nitrato de cálcio). Em todas as fases de desenvolvimento, os micronutrientes utilizados foram: 7,50 $\mathrm{g}$ de ácido bórico; $6,75 \mathrm{~g}$ de sulfato de manganês; $0,37 \mathrm{~g}$ de sulfato de cobre; $0,15 \mathrm{~g}$ de molibdato de sódio; $1,18 \mathrm{~g}$ de sulfato de zinco; 37,5 g de ferro.

Para o controle de pragas e doenças, efetuou-se, mediante o exame visual do agente, inseto ou patógeno, e de acordo com recomendações técnicas, o uso de produtos químicos registrados para a cultura.

A colheita foi realizada quando os frutos apresentaram pelo menos $60 \%$ do epicarpo na coloração vermelha, tendo início em setembro de 2012 e estendendo-se até novembro do mesmo ano.

As características produtivas avaliadas foram: número de frutos comerciais por planta (NFCP); massa média dos frutos (g) (MMF); produção por planta $\left(\mathrm{kg} \mathrm{planta}^{-1}\right)$ (PP); produtividade comercial estimada $\left(\mathrm{t} \mathrm{ha}^{-1}\right)(\mathrm{PCE})$; altura do primeiro rácemo $(\mathrm{cm})(\mathrm{APR})$ e número de rácemos por planta (NRP).

Para as características qualitativas, selecionaram-se dez frutos aleatoriamente de cada tratamento e avaliaram-se, três vezes durante as colheitas: diâmetros longitudinal (DL) e transversal dos frutos (DT) (mm); espessura média da polpa (EP) (mm); número médio de lóculos por fruto (NL); índice de maturação - obtido pela relação sólidos solúveis/acidez titulável; firmeza (N) - obtida com penetrômetro digital; $\mathrm{pH}$ - determinado no extra- to do suco de cinco frutos, com peagâmetro digital; acidez titulável - obtida em alíquota de $10 \mathrm{ml}$ de suco, ao qual foram adicionados $40 \mathrm{ml}$ de água destilada e três gotas do indicador azul de bromotimol alcoólico a 1\%, titulando-se com solução de $\mathrm{NaOH} 0,1 \mathrm{~N}$, até o ponto de viragem (\% de ácido cítrico); sólidos solúveis - teor obtido, com refratômetro manual, no suco de cinco frutos por parcela ( $\left.{ }^{\circ} \mathrm{Brix}\right)$.

Para determinação do estado nutricional do tomateiro, foi realizada amostragem de folhas no período de pleno florescimento da cultura, de acordo com a metodologia descrita por Malavolta et al. (1997). As amostras de folhas foram lavadas em água deionizada, colocadas para secar em estufa, com circulação de ar forçado, a $60^{\circ} \mathrm{C}$, até atingirem massa constante, sendo, então, moídas e submetidas à análise química, de acordo com a metodologia descrita por Bataglia et al. (1983).

Realizou-se análise de variância dos dados e as médias foram comparadas pelo teste de Tukey, a 5\% de probabilidade, com o programa AGROESTAT (Barbosa \& Maldonado Júnior, 2015).

\section{RESULTADOS E DISCUSSÃO}

Para todos os tratamentos avaliados, houve $100 \%$ de pegamento das enxertias, nos porta-enxertos 'Maxifort', 'Multifort' e na autoenxertia.

Não houve diferenças para todas as características avaliadas (Tabelas 1 e 2), com exceção para os teores de P, $\mathrm{Mg}$ e Ca (Tabela 3).

Foram obtidos, em média, cinco rácemos por haste, totalizando 20 rácemos por planta (Tabela 1). Charlo et al. (2009) obtiveram maior número de rácemos por planta quando utilizaram duas hastes por planta (14,21 rácemos planta $^{-1}$ ), o que evidencia que, à medida que se aumenta $\mathrm{o}$ número de hastes, maior será o número de rácemos por planta.

Para a altura do primeiro rácemo, observou-se média de $66,40 \mathrm{~cm}$, ou seja, valor elevado para tomateiros tutorados verticalmente, quando se compara com os valores obtidos por Charlo et al. (2009), que, avaliando o sistema de orientação com duas hastes em tomateiro, obtiveram valores de $34,68 \mathrm{~cm}$. Isto pode ter ocorrido em função do reduzido espaçamento entre plantas adotado neste trabalho $(0,40 \mathrm{~m})$, ocasionando mudanças na distribuição da radiação solar para as plantas, além da própria enxertia, que elevou a altura da muda.

Verifica-se, comparando-se com os dados de outros autores da literatura (Carvalho \& Tessarioli Neto, 2005; Marim et al., 2005; Charlo et al., 2009; Matos et al., 2012), conduzindo-se plantas de tomateiro sem uso da enxertia e variando o número de hastes de uma a duas, elevado número de frutos por planta (média de 99 frutos). Isso se 
deve ao fato de que plantas conduzidas com quatro hastes emitem maior número de rácemos e, consequentemente, produzem maior número de frutos. No entanto, o aumento do número de frutos ocasionou redução de sua massa, em função do aumento do número de hastes (média de 116 g por fruto). Matos et al. (2012), avaliando o desempenho de híbridos de tomateiro em dois sistemas de condução, com uma e duas hastes, obtiveram valores médios de $132 \mathrm{~g}$ para o cultivar Alambra. Charlo et al. (2009), trabalhando com o mesmo cultivar obtiveram valores de 110,38 g e 96,79 g, respectivamente, para condução com uma e duas hastes, inferiores ao obtido neste trabalho.

A redução da massa dos frutos em função do aumento do número de hastes por planta provavelmente ocorreu por causa do aumento excessivo de frutos-drenos por planta, ocasionando maior competição por fotoassimilados e, consequentemente, menor desenvolvimento dos frutos. Esses resultados também foram relatados por Oliveira et al. (1995), ao avaliarem número de ramos por planta e poda dos rácemos, em campo, e por Poerschke et al. (1995), em casa de vegetação.
Não houve efeito dos tratamentos sobre as características de produção por planta e produtividade comercial estimada. Entretanto, esses resultados são superiores aos relatados por Matos et al. (2012) e Carvalho \& Tessarioli Neto (2005). Possivelmente, a não ocorrência de diferença entre os tratamentos estará relacionada com o fato de que o maior número de hastes tenha estimulado a produção de maior quantidade de flores, além de maior área foliar fotossintetizante. Isto, aliado ao fornecimento de condições propícias às plantas (cultivo fertirrigado em substrato), proporcionou condições adequadas ao desenvolvimento das plantas.

Com relação às características de qualidade (Tabela 2), verifica-se média para diâmetro transversal dos frutos de $6,3 \mathrm{~cm}$, caracterizando-os como frutos de calibre médio, de acordo com as normas do MAPA (2002), valores semelhantes aos obtidos por Charlo et al. (2009) (6,6 e 6,5 $\mathrm{cm}$ para plantas conduzidas, respectivamente, com uma e duas hastes.

Já Carvalho \& Tessarioli Neto (2005), ao avaliarem o desempenho de híbridos de tomateiro em diferentes espaçamentos e sistemas de orientação, observaram que

Tabela 1: Número de rácemos por planta (NRP), altura do primeiro rácemo (APR), massa média de frutos (MMF), número de frutos comerciais por planta (NFCP), produção por planta (PP) e, produtividade comercial estimada (PCE), para a cultura do tomateiro, conduzido com quatro hastes e diferentes porta-enxertos, em fibra da casca de coco, em ambiente protegido

\begin{tabular}{lcccccc}
\hline Porta-enxertos & NRP & $\begin{array}{c}\text { APR } \\
(\mathbf{c m})\end{array}$ & $\begin{array}{c}\text { MMF } \\
(\mathbf{g})\end{array}$ & $\mathbf{N F C P}$ & $\begin{array}{c}\text { PP } \\
\left(\mathbf{k g ~ p l a n t a}^{-1}\right)\end{array}$ & $\begin{array}{c}\text { PCE } \\
\left(\mathbf{t ~ h a}^{-1}\right)\end{array}$ \\
\hline Maxifort & 5,00 & 65,08 & 119,0 & 100,0 & 11,29 & 141,06 \\
Multifort & 5,00 & 65,80 & 119,0 & 101,0 & 12,37 & 154,55 \\
Autoenxertia & 5,00 & 68,40 & 117,0 & 101,0 & 11,76 & 147,07 \\
Pé franco & 5,00 & 66,36 & 110,0 & 96,0 & 10,94 & 136,68 \\
\hline Média & 5,00 & 66,40 & 116,0 & 99,0 & 11,58 & 144,84 \\
\hline Teste F & $1,00^{\text {ns }}$ & $1,12^{\text {ns }}$ & $1,84^{\text {ns }}$ & $0,58^{\text {ns }}$ & $2,33^{\text {ns }}$ & $2,31^{\text {ns }}$ \\
DMS* & 0,39 & 5,49 & 0,01 & 13,92 & 1,66 & 20,76 \\
\hline CV $(\%)$ & 4,79 & 4,96 & 6,33 & 8,41 & 8,60 & 8,61 \\
\hline
\end{tabular}

*P < 0,05 pelo teste de Tukey. ns: não significativo. DMS: diferença mínima significativa. CV: coeficiente de variação.

Tabela 2: Espessura de polpa (EP), diâmetro longitudinal (DL) e diâmetro transversal (DT), número de lóculos (NL), pH, firmeza, acidez titulável (AT), sólidos solúveis totais (SST), e índice de maturação (IM) para a cultura do tomateiro 'Alambra', conduzida com quatro hastes em diferentes porta-enxertos, em fibra da casca de coco, sob ambiente protegido

\begin{tabular}{|c|c|c|c|c|c|c|c|c|c|}
\hline \multirow{2}{*}{ Porta-enxerto } & EP & DL & DT & NL & \multirow{2}{*}{ pH } & \multirow{2}{*}{$\frac{\text { Firmeza }}{(\mathbf{N})}$} & \multirow{2}{*}{$\frac{\mathrm{AT}}{(\% \text { ác.cítrico })}$} & \multirow{2}{*}{$\frac{\text { SST }}{\left({ }^{\circ} \text { Brix }\right)}$} & \multirow{2}{*}{ IM } \\
\hline & \multicolumn{4}{|c|}{$(\mathbf{m m})$} & & & & & \\
\hline Maxifort & 8,02 & 56,45 & 63,18 & 4,0 & 4,79 & 27,56 & 0,26 & 4,24 & 16,69 \\
\hline Multifort & 8,02 & 55,59 & 62,62 & 4,0 & 4,85 & 26,34 & 0,24 & 4,02 & 16,60 \\
\hline Autoenxertia & 8,37 & 58,91 & 62,63 & 4,0 & 4,84 & 28,64 & 0,24 & 4,25 & 18,09 \\
\hline Pé franco & 7,98 & 55,91 & 61,99 & 4,0 & 4,79 & 29,28 & 0,24 & 4,29 & 17,59 \\
\hline Média & 8,88 & 56,71 & 62,60 & 4,0 & 4,82 & 27,95 & 0,24 & 4,20 & 17,24 \\
\hline Teste F & $2,92 \mathrm{~ns}$ & $1,44 \mathrm{~ns}$ & 1,03 ns & $1,00 \mathrm{~ns}$ & 2,94 ns & 0,27 ns & 0,70 ns & $1,07 \mathrm{~ns}$ & $1,05^{\mathrm{ns}}$ \\
\hline DMS * & 0,43 & 5,11 & 1,94 & 0,33 & 3,06 & 0,24 & 0,04 & 0,47 & 2,86 \\
\hline $\mathrm{CV}(\%)$ & 3,21 & 5,42 & 1,86 & 5,15 & 6,59 & 3,10 & 9,81 & 6,82 & 9,97 \\
\hline
\end{tabular}

*P < 0,05 pelo teste de Tukey. ${ }^{\text {ns: }}$ não significativo. DMS: diferença mínima significativa. CV: coeficiente de variação

Rev. Ceres, Viçosa, v. 64, n.2, p. 186-191, mar/abr, 2017 
Tabela 3: Teores foliares de N, P, K, Mg, Ca, S, B, Fe, Mn, Zn e Cu, em plantas de tomateiro, conduzidas com quatro hastes, e diferentes porta-enxertos, em fibra da casca de coco, em ambiente protegido

\begin{tabular}{|c|c|c|c|c|c|c|}
\hline \multirow{2}{*}{ Porta-enxerto } & $\mathbf{N}$ & $\mathbf{P}$ & $\mathbf{K}$ & Mg & $\mathbf{C a}$ & $\mathbf{S}$ \\
\hline & \multicolumn{6}{|c|}{$\mathrm{g} \mathrm{kg}^{-1}$} \\
\hline Maxifort & 51,92 & $7,72 \mathrm{c}$ & 29,88 & $7,32 \mathrm{~b}$ & $23,47 \mathrm{a}$ & 7,87 \\
\hline Multifort & 53,24 & $7,96 \mathrm{bc}$ & 30,22 & $8,03 \mathrm{a}$ & $24,72 \mathrm{a}$ & 7,98 \\
\hline Autoenxertia & 53,05 & $8,77 \mathrm{ab}$ & 27,88 & $8,07 \mathrm{a}$ & $22,87 \mathrm{ab}$ & 7,53 \\
\hline Pé franco & 52,00 & $8,59 \mathrm{a}$ & 29,20 & $8,02 \mathrm{a}$ & $21,18 \mathrm{~b}$ & 7,88 \\
\hline Teste F & 0,52 ns & $10,45^{*}$ & $0,47^{\mathrm{ns}}$ & $6,31 *$ & $8,73^{*}$ & $2,74^{\mathrm{ns}}$ \\
\hline \multirow{2}{*}{ Porta-enxerto } & B & $\mathbf{F e}$ & \multicolumn{2}{|c|}{ Mn } & Zn & $\mathrm{Cu}$ \\
\hline & \multicolumn{6}{|c|}{$\mathrm{mg} \mathrm{kg}^{-1}$} \\
\hline Maxifort & 38,47 & 173,83 & \multicolumn{2}{|c|}{150,67} & 93,33 & 375,00 \\
\hline Multifort & 37,93 & 172,50 & \multicolumn{2}{|c|}{149,83} & 82,83 & 350,00 \\
\hline Autoenxertia & 38,24 & 164,83 & \multicolumn{2}{|c|}{157,00} & 86,00 & 391,67 \\
\hline Pé franco & 42,52 & 164,50 & \multicolumn{2}{|c|}{136,17} & 81,17 & 358,33 \\
\hline Teste F & 0,95 ns & $0,72^{\text {ns }}$ & \multicolumn{2}{|c|}{$1,22^{\mathrm{ns}}$} & 2,72 ns & $0,33^{\mathrm{ns}}$ \\
\hline
\end{tabular}

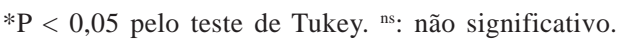

o cultivar Carmen apresentou maior produção de frutos de calibre médio, quando adotaram o espaçamento de 30 $\mathrm{cm}$ entre plantas, o que evidencia que, além do elevado número de frutos por planta, o espaçamento adotado de 0,40 m, no atual experimento também pode ter influenciado no calibre dos frutos.

Segundo esses mesmos autores, o aumento da produção de frutos médios com a diminuição do espaçamento entre plantas também foi observado em outros híbridos, por outros autores, como Streck et al. (1998), provavelmente graças à maior competição intraplanta pelos fotoassimilados.

Para as características de $\mathrm{pH}$, firmeza, acidez titulável e sólidos solúveis totais, os teores médios foram de 4,82; 27,95 N; 0,24\% ácido cítrico; e 4, $2^{\circ} \mathrm{Brix}$, respectivamente. Estes valores são semelhantes aos obtidos por Cardoso et al. (2006b), caracterizando física e físico-químicamente frutos de tomateiro oriundos de plantas enxertadas, em comparação com os de plantas pé franco.

Para o índice de maturação, ressalta-se que os resultados encontrados neste trabalho (média de 17,24) são superiores aos citados por diversos autores (Cardoso et al., 2006a; Loos et al., 2009), o que os classifica como de excelente qualidade, de acordo com Lopes (2000), por apresentarem "ratio" acima de 10. Além disso, esse índice estabelece uma relação entre o teor de sólidos solúveis e a acidez titulável, sendo indicativo do sabor e do estado de maturação do fruto (Chitarra \& Chitarra, 2005).

Com relação ao estado nutricional das plantas (Tabela 3), observou-se que os tratamentos com o porta-enxerto 'Maxifort' apresentaram os menores teores de $\mathrm{P}$ e $\mathrm{Mg}$, com média de 7,72 e 7,32 $\mathrm{g} \mathrm{kg}^{-1}$, respectivamente.

Este resultado pode ter ocorrido em função da enxertia, pois segundo Lee \& Oda (2003), a enxertia pode influenci- ar a absorção e translocação de fósforo, magnésio, nitrogênio e cálcio em plantas enxertadas, constituindo barreira para translocação desses elementos.

Já para o teor de $\mathrm{Ca}$, observaram-se menores teores em plantas pé franco $\left(21,18 \mathrm{~g} \mathrm{~kg}^{-1}\right)$. Segundo Tomaz et al. (2003), variações na eficiência de uso de cálcio em tecidos vegetais não são ainda bem compreendidas, porém sabese que a inativação de cálcio ocorre por ligação ou precipitação na forma de oxalato ou fosfato de cálcio, o que tem sido sugerido como causa para a baixa eficiência de utilização desse nutriente, considerado pouco móvel no floema (Marschner, 1995).

Apesar de não ter ocorrido diferenças entre os tratamentos para grande parte dos teores de macro e de micronutrientes foliares, quando se compara os resultados do trabalho em questão com os limites adequados sugeridos por Malavolta et al. (1997), verifica-se que o teor de $\mathrm{K}$ está abaixo do limite adequado para os tratamentos 'Maxifort', autoenxertia e pé franco. Da mesma forma, o teor de $\mathrm{Zn}$ apresenta-se ligeiramente acima e, o de $\mathrm{Cu}$, altamente elevado, em comparação com os valores estabelecidos como adequados por Malavolta et al. (1997). Os teores de $\mathrm{Cu}$ podem ter sido elevados pelo fato de o manejo fitossanitário da cultura do tomate exigir constantes aplicações de fungicidas cúpricos.

\section{CONCLUSÃO}

Nas condições em que o experimento foi realizado, os porta-enxertos 'Maxifort' e 'Multifort' não proporcionaram aumentos da produção e da qualidade dos frutos de tomateiro 'Alambra', conduzidos com quatro hastes. No entanto, é propícia sua utilização para produção de tomateiros cultivados em fibra da casca de coco, fertirrigado, em ambiente protegido. 


\section{REFERÊNCIAS}

Amafibra - Fibras e substratos agrícolas da Amazônia LTDA (2014) Fibra de coco. Disponível em: <www.amafibra.com.br>. Acessado em: 20 de janeiro de 2014

Barbosa JC \& Maldonado Junior W (2015) AgroEstat - sistema para análises estatísticas de ensaios agronômicos. Jaboticabal, FCAV/UNESP. 396p

Bataglia OC, Furlani AMC, Teixeira JPF, Furlani PR \& Gallo JR (1983) Métodos de análise química de plantas. Campinas, Instituto Agronômico. 48p. (Boletim Técnico, 78).

Cardoso SC, Soares ACF, Brito AS, Carvalho LA \& Ledo CAS (2006a) Viabilidade de uso do híbrido Hawaii 7996 como portaenxerto de cultivares comerciais de tomate. Bragantia, 65:89-96.

Cardoso SC, Soares ACF, Brito AS, Carvalho LA, Peixoto CC, Pereira ME \& Goes E (2006b) Qualidade de frutos de tomateiro com e sem enxertia. Bragantia, 65:269-274.

Carvalho LA \& Tessarioli Neto J (2005) Produtividade de tomate em ambiente protegido, em função do espaçamento e número de ramos por planta. Horticultura Brasileira, 23:986-989.

Castellane PD \& Araújo JAC (1994) Cultivo sem solo: Hidroponia. Jaboticabal, FUNEP. 43p.

Charlo HCO, Souza SC, Castoldi R \& Braz LT (2009) Desempenho e qualidade de frutos de tomateiro em cultivo protegido com diferentes números de hastes. Horticultura Brasileira, 27:144-149.

Chitarra MIF \& Chitarra AB (2005) Pós-colheita de frutos e hortaliças: fisiologia e manuseio. $2^{\mathrm{a}}$ ed. Lavras, UFLA. 785p.

Clause Vegetable Seeds (2013) Produtos Globais. Disponível em: <http:// http://hmclause.com/pt-br/produtos-globais/>. Acessado em: 29 de março de 2013.

FAO (2013) Production Crops. Disponível em: <http:// faostat.fao.org/site/339/default.aspx >. Acessado em: 05 de abril de 2013.

Filgueira FAR (1982) Cultura e comercialização de hortaliças. 2a ed. São Paulo, Agronômica Ceres. 50p.

Flores FB, Sánchez-Bel P, Estan MT, Martinez-Rodriguez MM, Moyano E, Morales B, Campos JF, Garcia-Abellán JO, Egea MI, Férnandez-Garcia N, Romojaro F \& Bolarín MC (2010) The effectiveness of grafting to improve tomato fruit quality. Scientia Horticulturae, 125:211-217.

Gruda N (2009) Do soilless culture systems have an influence on product quality of vegetables? Journal Applied Botany Food Quality, 82:141-147.

He Y, Zhu Z, Yang J, Ni X \& Zhu B (2009) Grafting increases the salt tolerance of tomato by improvement of photosynthesis and enhancement of antioxidant enzymes activity. Environmental and Experimental Botany, 66:270-278.

Lee JM \& Oda M (2003) Grafting of herbaceous vegetable and ornamental crops. Horticultural review, 28:61-124.

Loos RA, Caliman FRB \& Silva DJH (2009) Enxertia, produção e qualidade de tomateiros cultivados em ambiente protegido. $\mathrm{Ci}$ ência Rural, 39:232-253.

Lopes MC (2000) Influência do estádio das mudas e de dois portaenxertos no desenvolvimento do tomateiro (Lycopersicon esculentum Mill), híbrido Momotaro. Tese de doutorado. Universidade estadual Paulista "Júlio de Mesquita Filho", Botucatu. 89p.

Louws FJ, Rivard CL \& Kubota C (2010) Grafting fruiting vegetables to manage soilborne pathogens, foliar pathogens, arthropods and weeds. Scientia Horticulturae, 127:127-146.
Malavolta E, Vitti GC \& Oliveira SA (1997) Avaliação do estado nutricional das plantas: princípios e aplicações. $2^{\mathrm{a}}$ ed. Piracicaba, Potafós. 319p.

Marim BG, Silva DJH, Guimarães MA \& Belfort G (2005) Sistemas de tutoramento e condução do tomateiro visando produção de frutos para consumo in natura. Horticultura Brasileira, 23:951-955.

Marschner H (1995) Mineral nutrition of higher plants. London, Academic Press. 889p.

Martínez-Ballesta CM, Alcaraz-López C, Muries B, Mota-Cadenas C \& Carvajal M (2010) Physiological aspects of rootstock scion interactions. Scientia Horticulturae, 127:112-118.

Matos ES, Shirahige FH \& Melo PCT (2012) Desempenho de híbridos de tomate de crescimento indeterminado em função de sistemas de condução de plantas. Horticultura Brasileira, 30:240245 .

MAPA - Ministério Da Agricultura Pecuária e Abastecimento (2002) Normas de identificação, qualidade, acondicionamento, embalagem e apresentação do tomate. DOU, 19/09/1995, Seção 1, p. 14464 .

Oliveira VR, Campos JP, Fontes PCR \& Reis FP (1995) Efeito do número de hastes por planta e poda apical na produção classificada de frutos de tomateiro (Lycopersicon esculentum Mill.). Ciência e Prática, 19:414-419.

Poerschke PRC, Buriol GA, Streck NA \& Estefanel V (1995) Efeito de sistemas de poda sobre o rendimento do tomateiro cultivado em estufa de polietileno. Ciência Rural, 25:379-384.

Ruiter Seeds (2013) Rootstock. Disponível em: <https:// www.deruiterseeds.com/us/en/rootstock/Maxifort.html>. Acessado em: 15 de abril de 2013.

Schwarz D, Öztekin GB, Tuzel Y, Bruckner B \& Krumbein A (2012) Rootstocks can enhance tomato growth and quality characteristics at low potassium supply. Scientia Horticulturae, 149:70-79.

Silva DJH, Sediyama MAN, Mata AC, Rocha DM \& Picanço MC (1997) Produção de frutos de tomateiro (Lycopersicon esculentum Mill) em quatro sistemas de cultivo. Revista Ceres, 44:129-141.

Streck NA, Buriol GA, Andriolo JL \& Sandri MA (1998) Influência da densidade de plantas e da poda apical drástica na produtividade do tomateiro em estufa de plástico. Pesquisa Agropecuária Brasileira, 33:1105-1112

Tomaz MA, Silva SR, Sakiyama NS \& Martinez HEP (2003) Eficiência de absorção, translocação e uso de cálcio, magnésio e enxofre por mudas enxertadas de Coffea arábica. Revista Brasileira de Ciência do Solo, 27:885-892. 